\title{
Evaluating continuous and autonomous snow water equivalent measurements by a cosmic ray sensor on a Swiss glacier
}

Rebecca Gugerli ${ }^{1}$, Nadine Salzmann ${ }^{1}$, Matthias Huss ${ }^{1,2}$, and Darin Desilets ${ }^{3}$

${ }^{1}$ Department of Geosciences, University of Fribourg, Fribourg, Switzerland

${ }^{2}$ Laboratory of Hydraulics, Hydrology and Glaciology (VAW), ETH Zurich, Zurich, Switzerland

${ }^{3}$ Hydroinnova LLC, Albuquerque, NM, USA

Correspondence: Rebecca Gugerli (rebecca.gugerli@unifr.ch)

\section{Field data}

Table 1 shows the summary of each field survey conducted on Plaine Morte with all observed and calculated parameters. 


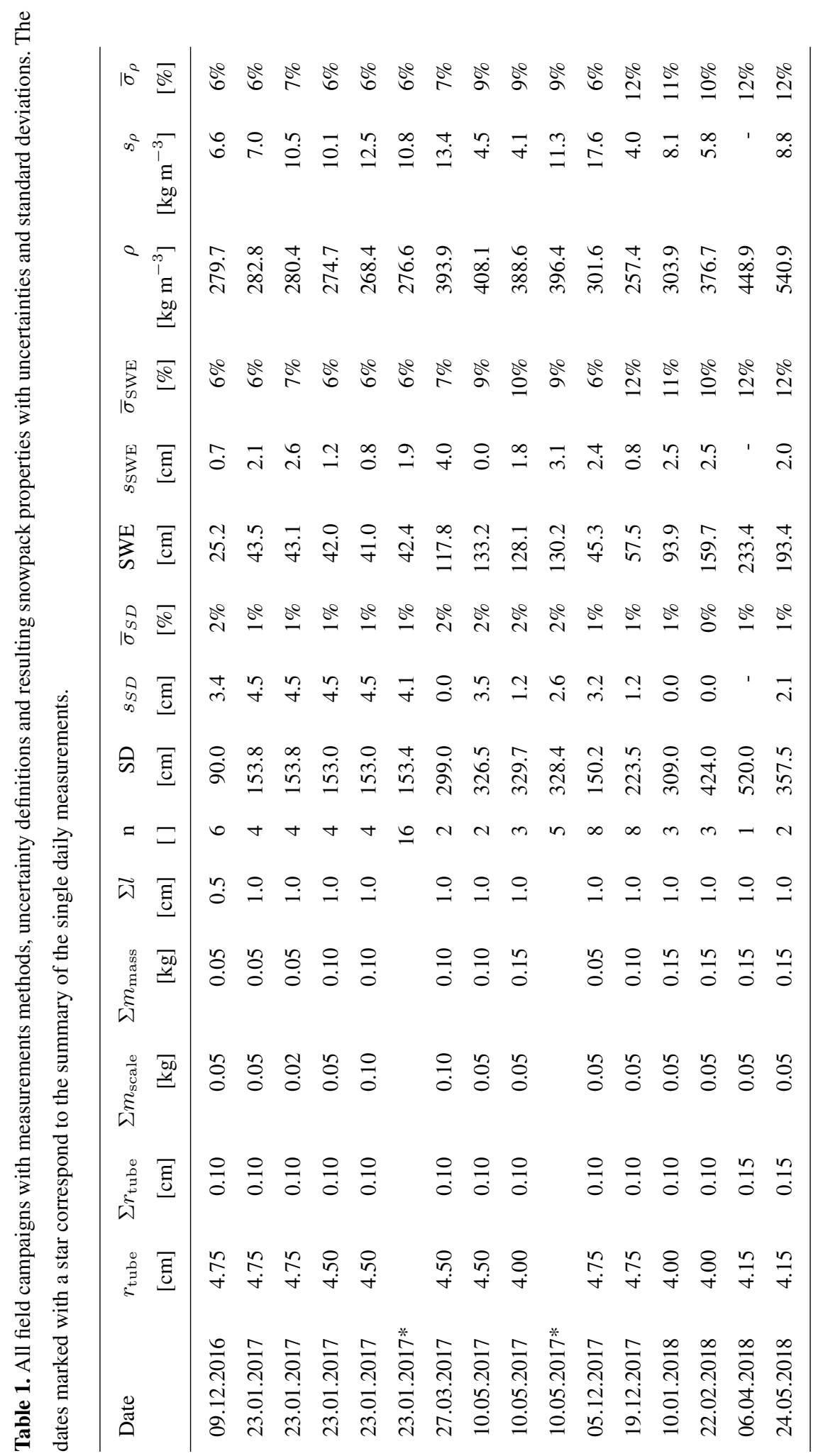

